\title{
Bertiella studeri Infection in Children, Sri Lanka
}

\author{
Anjalie Amarasinghe, Thanh H. Le, Susiji Wickramasinghe
}

We provide a detailed molecular and phylogenetic description of Bertiella studeri tapeworms infecting children in Sri Lanka. Our findings can be used to identify multiple species of Bertiella tapeworms that can infect human hosts in the Old World.

$\mathrm{T}$ he genus Bertiella, which has 29 known tapeworm species, belongs to the subfamily Anoplocephalinae of the Anoplocephalidae family (1). These tapeworms are common parasites in the small intestine of primates (2). Of these species, only B. studeri, B. mucronata, and B. satyri (3), which was recently redescribed as a different species $(4)$, can infect humans $(4,5)$. Children acquire this infection usually by eating contaminated fruits or by ingesting contaminated soil. The earliest identified cases of human bertiellosis in Sri Lanka occurred in 1975; these cases and 1 further case were reported in 1976. Six cases were reported in the literature from 1988-2006 (6). The most recent report was in 2006 from Rathnapura, Sabaragamuwa Province, Sri Lanka (7).

The morphologic, taxonomic, and molecular analysis of several species classified in the family $\mathrm{An}$ oplocephalidae are not well documented (6). A recent study has identified an unexpected genetic diversity that suggests the existence of several Bertiella species in primates and humans $(6,8)$. Multiple species of Bertiella tapeworms may infect humans in the New World and the Old World. It is not certain whether the Old World and New World Bertiella infections, previously all identified as B. studeri or B. mucronata, actually represent multiple different species; the true taxonomic distinction and geographic distribution of these 2 species are not entirely clear (6). Furthermore, diagnosis entirely based on egg morphology, size, and geographic distribution is insufficient to discriminate B. studeri tapeworms from other Bertiella spp. infecting humans (9).

Author affiliations: University of Peradeniya, Peradeniya, Sri Lanka (A. Amarasinghe, S. Wickramasinghe); Vietnam Academy of Science and Technology, Hanoi, Vietnam (T.H. Le)

DOI: https://doi.org/10.3201/eid2608.200324
This study provides the molecular analysis of the B. studeri tapeworms infecting children in Sri Lanka and describes phylogenetic relationships for this species. The Ethics Review Committee in the Faculty of Medicine, University of Peradeniya, Sri Lanka approved this study (protocol no. 2019/EC/03).

\section{The Study}

We conducted a retrospective study using tapeworm proglottids (Appendix Figure 1, https:/ / wwwnc.cdc. gov/EID/article/26/8/20-0324-App1.pdf) from 24 pediatric patients referred to the Department of Parasitology, Faculty of Medicine, University of Peradeniya, Peradeniya, Sri Lanka, during 2007-2017. Patients were all $<10$ years of age (range $3.5-9$ years). No other epidemiologic data were available.

We extracted genomic DNA separately using a commercial DNA extraction kit (PureLink; Invitrogen, https://www.thermofisher.com). We amplified 2 mitochondrial markers, nicotinamide adenine dinucleotide hydrogenase subunit 1 gene (NAD1) and cytochrome c oxidase subunit 1 gene (COX1), and 3 nuclear ribosomal markers, the second internal transcribed spacer region (ITS2), 28S large subunit ribosomal region (28S), and 18S rRNA gene (18S), using the specified primers and PCR conditions (Appendix Table). We subjected the PCR products to Sanger sequencing; only the ethanol-preserved samples provided a sufficient amount of DNA for sequencing (Appendix). We inferred molecular phylogenetic analysis and evolutionary history using maximumlikelihood and Bayesian methods.

Phylogenetic analysis identified a monophyletic group of Bertiella species in all 5 maximumlikelihood trees. The NAD1 region revealed several clades within the Bertiella monophyletic group (Figure 1, panel A); sequence similarity search identified 90.19\% match with Bertiella species (GenBank accession no. JQ771111). The COX1 sequence similarity search identified $95.10 \%$ match with Bertiella species (GenBank accession no. JQ771106); COX1 analysis identified 2 clades in the Bertiella monophyletic 

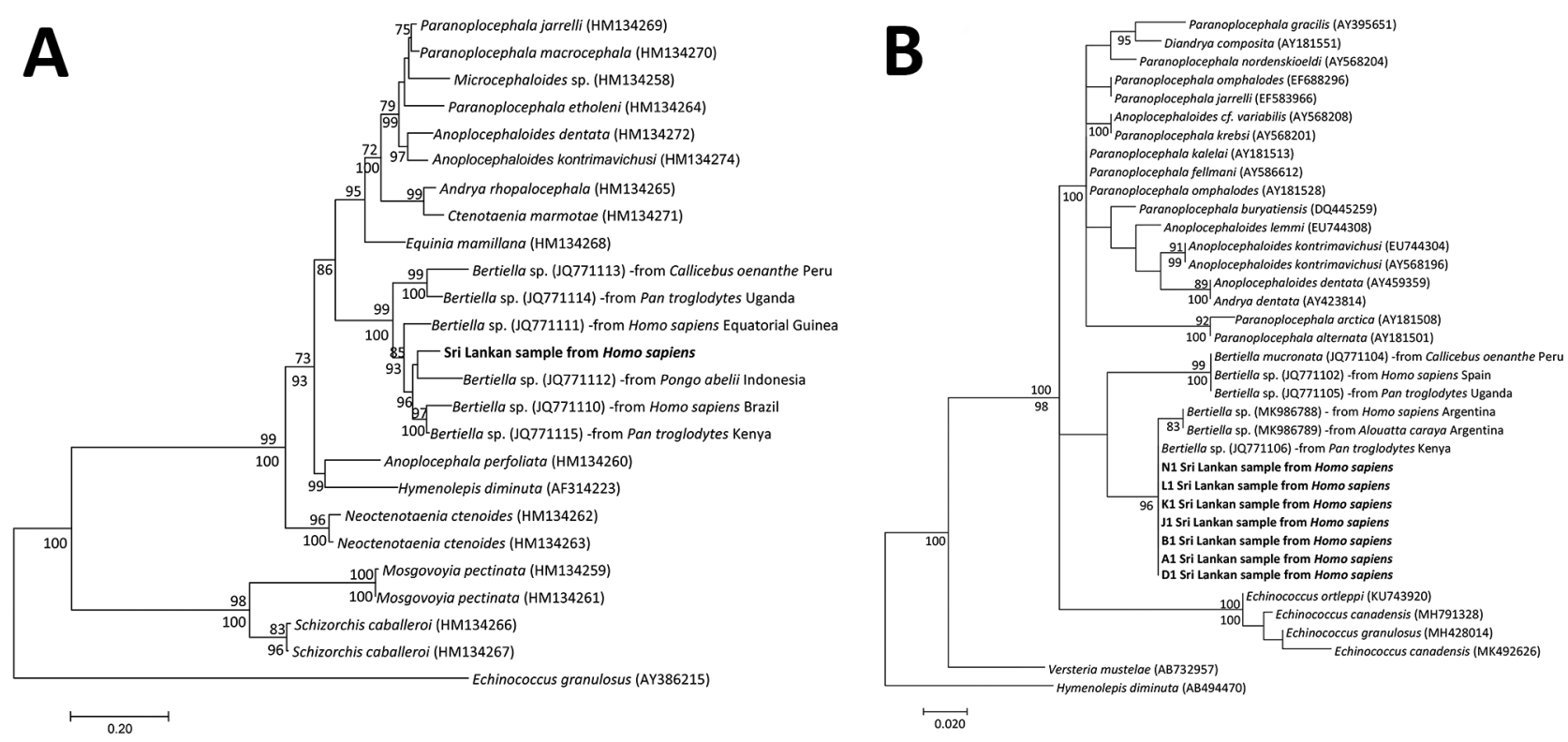

Figure 1. Molecular phylogeny of the mitochondrial markers in a study of Bertiella tapeworms in children in Sri Lanka. Bold text indicates B. studeri samples from Sri Lanka. A) Maximum-likelihood tree containing 25 taxa constructed by the analysis of partial NAD1 sequence alignment. B) Maximum-likelihood tree containing 37 taxa was constructed by the analysis of partial COX1 sequence alignment. Numbers above the nodes indicate the percentages of 1,000 nonparametric bootstrap pseudoreplicates $(>70)$ and below the nodes the percentages of 1,000 Bayesian posterior probabilities (>70). GenBank accession numbers are provided for reference sequences. Scale bars represent nucleotide divergence.

group (Figure 1, panel B). Bertiella species from human hosts, acquired in Equatorial Guinea and Argentina, and B. mucronata (New World) from Callicebus oenanthe monkeys were separated from the Sri Lanka clade (Figure 1, panel B).

The ITS2 sequences showed $99.35 \%$ similarity with B. studeri (GenBank accession no. AB586129) and $100 \%$ similarity with Bertiella species (GenBank accession no. JQ771096). All the B. studeri sequences from Asia are in 1 clade. The second clade included 3 sequences from Pan troglodytes chimpanzee in Kenya, 1 from a human infection acquired in Equatorial Guinea, and 1 from a human host in Brazil (Figure 2, panel A). The 28S rRNA gene analysis revealed 2 clades for Bertiella from humans and nonhuman primates (Figure 2, panel B). The sequence similarity search revealed $94.66 \%$ similarity with Bertiella species (GenBank accession no. KJ888951). Furthermore, we identified a single-nucleotide polymorphism in $28 \mathrm{~S}$ rRNA region ( $\mathrm{T}$ to $\mathrm{C}$ ) between the samples from Sri Lanka that suggest genetic diversity (Appendix Figure 2, panel A). In the ML tree for $18 \mathrm{~S}$ rRNA region, Sri Lanka samples and $B$. studeri obtained from Macaca fascicularis macaque formed a single clade (Figure 2, panel C). The sequence similarity search for $18 \mathrm{~S}$ rRNA region identified $99.84 \%$ match with B. studeri (GenBank accession no. GU323706).
Furthermore, $18 \mathrm{~S}$ rRNA region in the Sri Lanka samples have a single-nucleotide polymorphism ( $\mathrm{T}$ to $\mathrm{C}$ ) with the Bertiella sequence from $M$. fascicularis (Appendix Figure 2, panel B).

Records we examined showed patients had white, flat, motile worm segments in stools, and some patients had reported abdominal disturbances and intermittent diarrhea. Previous studies reported recurrent abdominal pain and continuous perianal itching, anorexia, weight loss, and intermittent diarrhea in infected patients (6); however, these symptoms are not unique to Bertiella infection, and so the correct diagnosis of bertiellosis is important. Treatment failure for B. studeri worms using niclosamide was reported in a 30-month-old patient in Sri Lanka in 2004 (10) and in a 5-year-old patient in Sabaragamuwa Province, Sri Lanka (7).

\section{Conclusions}

Our results suggest an intraspecific diversity of Bertiella tapeworms. Such diversity may occur according to the host and the geographic location. A previous study conducted by Doležalová et al. $(8,11)$ has suggested a broad genetic diversity among the Bertiella species in primates and humans; further studies are required to support this suggestion. According to the available demographic data, most of the patients resided in Central 
Province, Sri Lanka; the most likely reason that they comprised most patients is the Bertiella tapeworm reservoir hosts, particularly Ceylon torque monkey (Macaca sinica) and gray langur (Presbytis entellus), that inhabit this region $(12,13)$. Over time, these monkey populations have lost their habitats due to deforestation and rapid urbanization in Sri Lanka; they are now regular visitors in suburban and urban areas scavenging for food near human settlements, which has increased human exposure to B. studeri infection $(14,15)$.

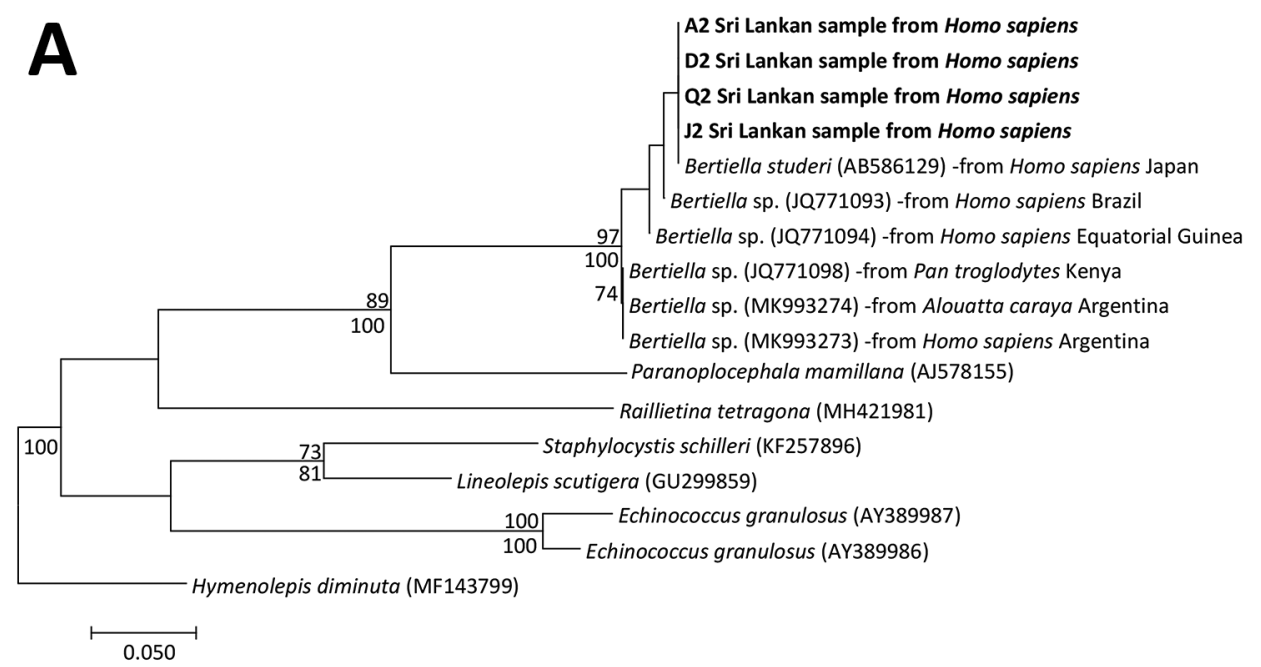

B

70_ Bertiella sp. (MG099776) - from Rattus tanezumi Vietnam B Bertiella anapolytica (JN683717) $84100 \_$Bertiella trichosuri (JN683722) Bertiella foederata (JN683720)

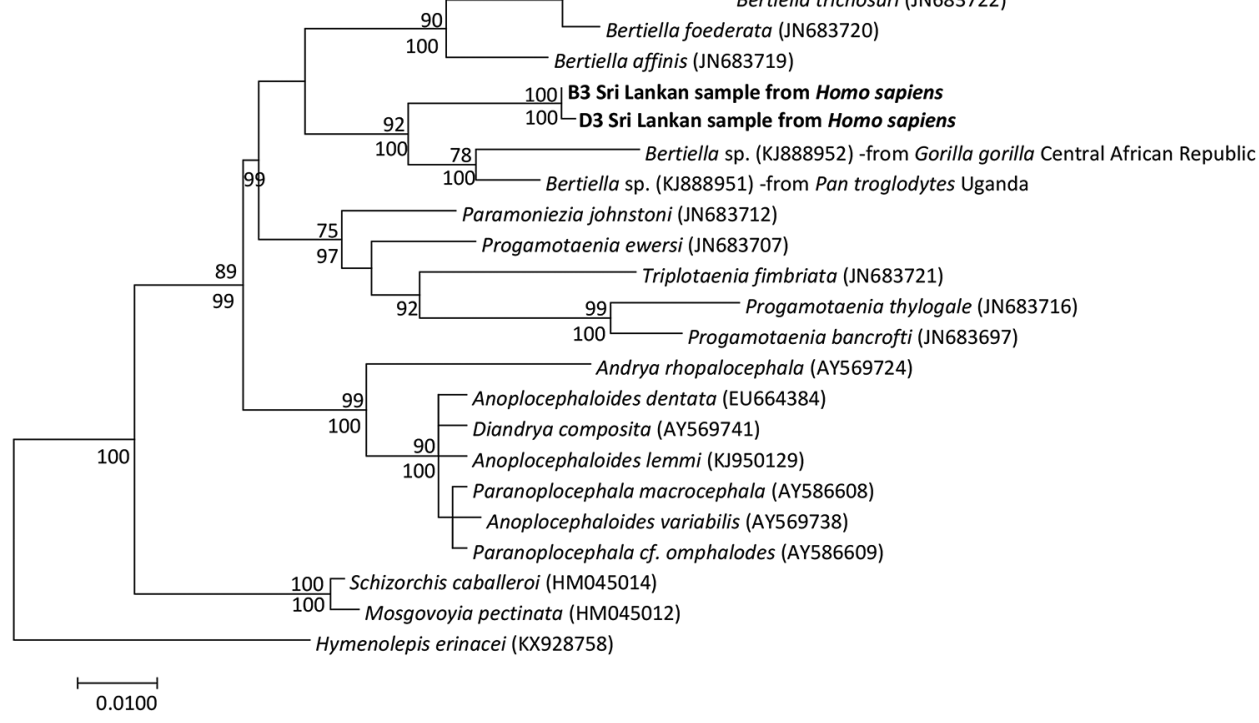
100 B3 Sri Lankan sample from Homo sapiens 100 D3 Sri Lankan sample from Homo sapiens Bertiella sp. (KJ888952) -from Gorilla gorilla Central African Republic Pan troglodytes Ugand

Figure 2. Molecular phylogeny of the nuclear ribosomal markers in study of Bertiella tapeworms in children in Sri Lanka. Bold text indicates Bertiella studeri samples from Sri Lanka. A) Maximumlikelihood tree containing 17 taxa, constructed by the analysis of partial ITS2 sequence alignment. B) Maximum likelihood tree containing 24 taxa, constructed by the analysis of partial $28 \mathrm{~S}$ sequence alignment. C) Maximumlikelihood tree containing 13 taxa, constructed by the analysis of partial $18 \mathrm{~S}$ sequence alignment. Numbers above the nodes indicate the percentages of 1,000 nonparametric bootstrap pseudoreplicates $(>70)$ and below the nodes the percentages of 1,000 Bayesian posterior probabilities (>70). GenBank accession numbers are provided for reference sequences. Scale bars represent nucleotide divergence.

\footnotetext{
C E4 Sri Lankan sample from Homo sapiens 14 Sri Lankan sample from Homo sapiens J4 Sri Lankan sample from Homo sapiens

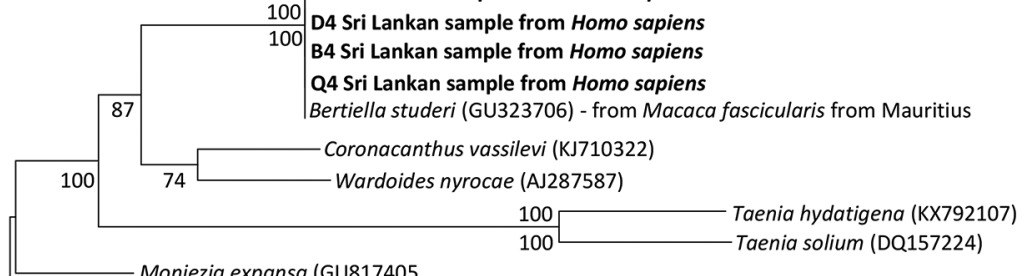

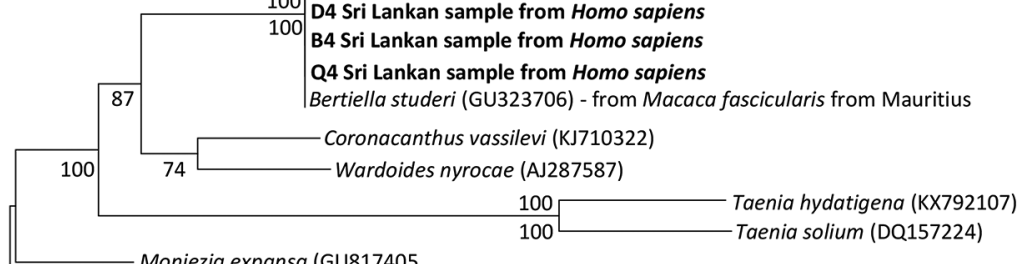

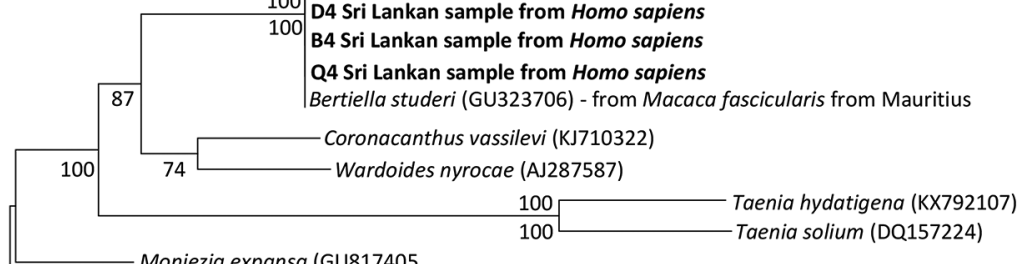
- Moniezia expansa (GU817405 -Hymenolepis diminuta (AF286983)
} 
Unavailability of molecular data for B. studeri 28S, COX1, and NAD1 markers in GenBank was a constraint that we encountered during phylogenetic analysis. In our study, we generated molecular data for 2 mitochondrial markers (NAD1, COX1), and 3 nuclear ribosomal markers (28S, 18S, ITS2) and submitted them to GenBank (Appendix). The molecular data obtained can be used for further analysis in diagnostics, to discern phylogenetic relationships and evolutionary correlations, and to understand the transmission dynamics of B. studeri tapeworms. Our data may also be used to assist in elucidating if multiple species of Bertiella sp. tapeworms infect human hosts in the Old World.

This study was funded by the University Research Grant (no. URG/2018/31/M), University of Peradeniya, Sri Lanka.

A.A. carried out the laboratory work, sequence analysis, and wrote the manuscript with input from all authors. T.H.L. carried out DNA sequencing. S.W. performed sequence analysis, manuscript writing, and finalized the manuscript. S.W. had the final responsibility for the decision to submit for publication. All authors reviewed the draft and approved the decision to submit for publication.

\section{About the Author}

Ms. Amarasinghe is a research assistant in the Department of Parasitology, Faculty of Medicine, University of Peradeniya, Sri Lanka. She is particularly interested in parasitology research.

\section{References}

1. Beveridge I. Family Anoplocephalidae Cholodkovsky, In: Khalil LF, Jones A, Bray RA, editors. Keys to the cestode parasites of vertebrates. Cambridge: CAB International; 1994. p. 315-66.

2. Stiles CW, Hassall A. Bertiella, new name for the cestode genus Bertia Blanchard, 1891. Science. 1902;16:434. https://doi.org/10.1126/science.16.402.434

3. Blanchard R. On the helminths of anthropoid primates [in French]. Mem Soc Zool Fr. 1891;4:186-96.

4. Foitová I, Mašová S, Tenora F, Koubková B, Hodová I, Vyskočilová $\mathrm{M}$, et al. Redescription and resurrection of Bertiella satyri (Cestoda, Anoplocephalidae) parasitizing the orangutan (Pongo abelii) in Indonesia. Parasitol
Res. 2011;109:689-97. https://doi.org/10.1007/ s00436-011-2300-0

5. Chandler AC. New records of Bertiella satyri (Cestoda) in man and apes. Parasitology. 1925;17:421-5. https://doi.org/ 10.1017/S0031182000004844</jrn>

6. Sapp SGH, Bradbury RS. The forgotten exotic tapeworms: a review of uncommon zoonotic Cyclophyllidea. Parasitology. 2020;147:533-58. https://doi.org/10.1017/ S003118202000013X</jrn>

7. Morawakkorala RN, Senarathna AMRD, de Alwis ACD, Abeywardana SP. Two cases of monkey tapeworm (Bertiella studeri) infestation from Sabaragamuwa Province. Sri Lanka Journal of Child Health. 2006;35:34-5. https://doi.org/10.4038/sljch.v35i1.7</jrn>

8. Doležalová J, Vallo P, Petrželková KJ, Foitová I, Nurcahyo W, Mudakikwa A, et al. Molecular phylogeny of anoplocephalid tapeworms (Cestoda: Anoplocephalidae) infecting humans and non-human primates. Parasitology. 2015; 142:1278-89. https://doi.org/10.1017/S003118201500058X

9. Galán-Puchades MT, Fuentes MV, Mas-Coma S. Morphology of Bertiella studeri (Blanchard, 1891) sensu Stunkard (1940) (Cestoda: Anoplocephalidae) of human origin and a proposal of criteria for the specific diagnosis of bertiellosis. Folia Parasitol (Praha). 2000;47:23-8. https://doi.org/ 10.14411/fp.2000.005</jrn>

10. Gallella SD, Gunawardena GS, Karunaweera ND. Bertiella studeri infection: resistance to niclosamide. Ceylon Med J. 2004;49:65. https://doi.org/10.4038/cmj.v49i2.3267

11. Servián A, Zonta ML, Cociancic P, Falcone A, Ruybal P, Capasso S, et al. Morphological and molecular characterization of Bertiella sp. (Cestoda, Anoplocephalidae) infection in a human and howler monkeys in Argentina. Parasitol Res. 2020;119:1291-300. https:// doi.org/10.1007/ s00436-020-06615-5

12. Huffman MA, Nahallage CA, Hasegawa H, Ekanayake S, De Silva LG, Athauda IR. Preliminary survey of the distribution of four potentially zoonotic parasite species among primates in Sri Lanka. J Natl Sci Found Sri Lanka. 2013;41:319. https:// doi.org/10.4038/jnsfsr.v41i4.6246

13. Dissanaike AS. Parasitic zoonoses in Sri Lanka: an update. Ceylon Med J. 2002;47:46-7. https:/ / doi.org/10.4038/ cmj.v47i2.3450

14. Furtado AP, Batista EJ, Gonçalves EC, Silva AM, Melo FT, Giese EG, et al. Human bertielliasis in Amazonia: case report and challenging diagnosis. PLoS Neg1 Trop Dis. 2012;6:e1580. https:// doi.org/10.1371/journal.pntd.0001580

15. Paçô JM, Campos DM, Araújo JL. Human bertiellosis in Goiás, Brazil: a case report on human infection by Bertiella sp. (Cestoda: Anoplocephalidae). Rev Inst Med Trop São Paulo. 2003;45:159-61. https://doi.org/10.1590/ S0036-46652003000300008

Address for correspondence: Susiji Wickramasinghe, Department of Parasitology, Faculty of Medicine, University of Peradeniya, Peradeniya, 20400, Sri Lanka; email: susijij@pdn.ac.lk or susijijp@yahoo.co.jp 